\title{
Facet joint injections for management of low back pain: a clinically focused review
}

\author{
Hyung-Sun Won ${ }^{1,2}$, Miyoung Yang ${ }^{1,2}$, and Yeon-Dong Kim ${ }^{2,3}$ \\ 'Department of Anatomy, Wonkwang University School of Medicine, ${ }^{2} J e s a e n g-E u i s e$ \\ Clinical Anatomy Center, Wonkwang University School of Medicine, ${ }^{3}$ Department of \\ Anesthesiology and Pain Medicine, Wonkwang University Hospital, Wonkwang University \\ School of Medicine, Iksan, Korea
}

Received December 17, 2019

Revised January 7, 2020

Accepted January 7, 2020

\section{Corresponding author}

Yeon-Dong Kim, M.D., Ph.D.

Department of Anesthesiology and

Pain Medicine, Wonkwang University

Hospital, Wonkwang University

School of Medicine, 895 Muwang-ro,

Iksan 54538, Korea

Tel: 82-63-859-1562

Fax: 82-63-857-5472

E-mail: kydpain@hanmail.net

\section{ORCID}

https://orcid.org/0000-0003-0404-2657
Lumbar facet joints have been implicated in chronic low back pain in up to $45 \%$ of patients with low back pain (LBP). Facet joint pain diagnosis and management are always challenging for pain physicians. Facet joint pain is not diagnosed by specific demographic features, pain characteristics, or physical findings, even though electrodiagnostic studies and imaging modalities are available. Although comparative local anesthetics or placebo saline injections can be used, diagnostic blocks are the only reliable diagnostic measures according to the current literature. Treatment of chronic LBP arising due to facet joint includes intraarticular injections, medial branch blocks, and radiofrequency neurotomy. However, the evidence of their clinical efficacy is continuously under scrutiny. Pain physicians must have a detailed understanding of the spinal anatomy in order to perform safe and effective interventional procedures. This review outlines the important aspects of spinal anatomy as they relate to interventional pain management related to facet joint injections. Additionally, we provide a comprehensive review of the procedure and clinical evidence.

Keywords: Facet joint injection; Imaging-guided injections; Interventional spinal procedures; Low back pain; Zygapophyseal joint.

\section{INTRODUCTION}

Interventional pain management has gained significant interest in the twenty-first century. The evolution of interventional pain management is denoted by an unprecedented development and progress in chronic pain management, specifically that utilizing interventional techniques. The National Uniform Claim Committee defined interventional pain management as the discipline of medicine that is dedicated to the diagnosis and treatment of pain disorders, using interventional techniques in managing various types of pain [1]. Despite the theoretical and practical comprehensiveness of the above definition, the applicability, relevance, and role of interventional approaches in pain management remain vague.

Spinal pain is a complex phenomenon that is difficult to define. Pain arising from various structures of the spine constitutes the majority of chronic pain disorders. These complexities further enhance the uncertainty related to the clinical evidence in spinal pain management.

For spinal pain, interventional techniques include minimally invasive procedures, such as needle placement in targeted areas for injecting drugs, ablation of targeted nerves, and surgical procedures, for example, radiofrequency ablation, discectomy, and spinal cord stimulator implantation [2]. Intervention techniques have been continuously refined and developed with advancements in imaging techniques, anatomical and chemical mediation knowledge, and preci-

This is an Open Access article distributed under the terms of the Creative Commons Attribution Non-Commercial License (http://creativecommons.org/licenses/by-nc/4.0) which permits unrestricted non-commercial use, distribution, and reproduction in any medium, provided the original work is properly cited. 
sion diagnostic and therapeutic injection techniques. The reported success rates of non-operative treatments establish their importance in the management of chronic spinal pain.

Lower back pain (LBP) is the most common form of spinal pain, with chronicity and severity that surpass those of cancer pain [2]. The annual prevalence of chronic LBP ranges from $15 \%$ to $45 \%$ (point prevalence, $30 \%$; lifetime prevalence, 54-80\%) [3]. Due to such an overwhelmingly high incidence, physicians of multiple specialties perform interventional techniques in various settings $[4,5]$. The frequency of application varies depending on the nature of the procedures and physicians. To date, diagnostic and therapeutic interventional techniques have been proven valid and effective, suggesting the importance of structural interventional pain management.

Among the various structures of the spine, facet joints are considered one of the most common causes of LBP [6]. Facet joint pain (FJP) is more common in the older population due to degeneration, inflammation, and repetitive injury, causing pain with joint movement [7]. Therefore, facet joint interventions, including intraarticular facet joint steroid injections, medial branch blocks, and radiofrequency denervation of the medial branch nerves, are commonly performed in clinical practice. This review aimed to summarize the existing information on FJP regarding its epidemiology, pathophysiology, and related anatomy, as well as the clinical evidence for the management of LBP.

\section{BASIC ANATOMY}

\section{Joint structure}

The facet joints (or zygapophyseal joints) are a set of plane types of synovial joints between the articular processes of two adjacent vertebrae, enveloped by articular capsules [8-10]. Articular cartilage covers the facets of the articular processes in each joint (Fig. 1), and a thin and sleeve-like synovial membrane (inner layer of the capsule) attaches to their margin. The outer tough fibrous layer of the capsule surrounds the synovial membrane (Fig. 2). Their size, shape, and topology vary with the vertebral level.

Synovial variety of the facet joint is simple in the cervical and thoracic regions, whereas it is very complex in the lumbar region [9]. Engel and Bogduk [11] have clarified three types of lumbar intracapsular structures that have been regarded as zygapophyseal lumbar specializations (Fig. 2). First is adipose

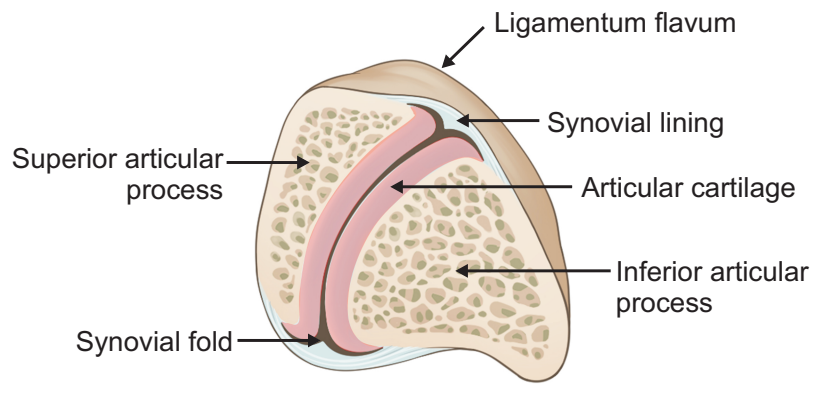

Fig. 2. A transverse section of the lumbar facet joint.

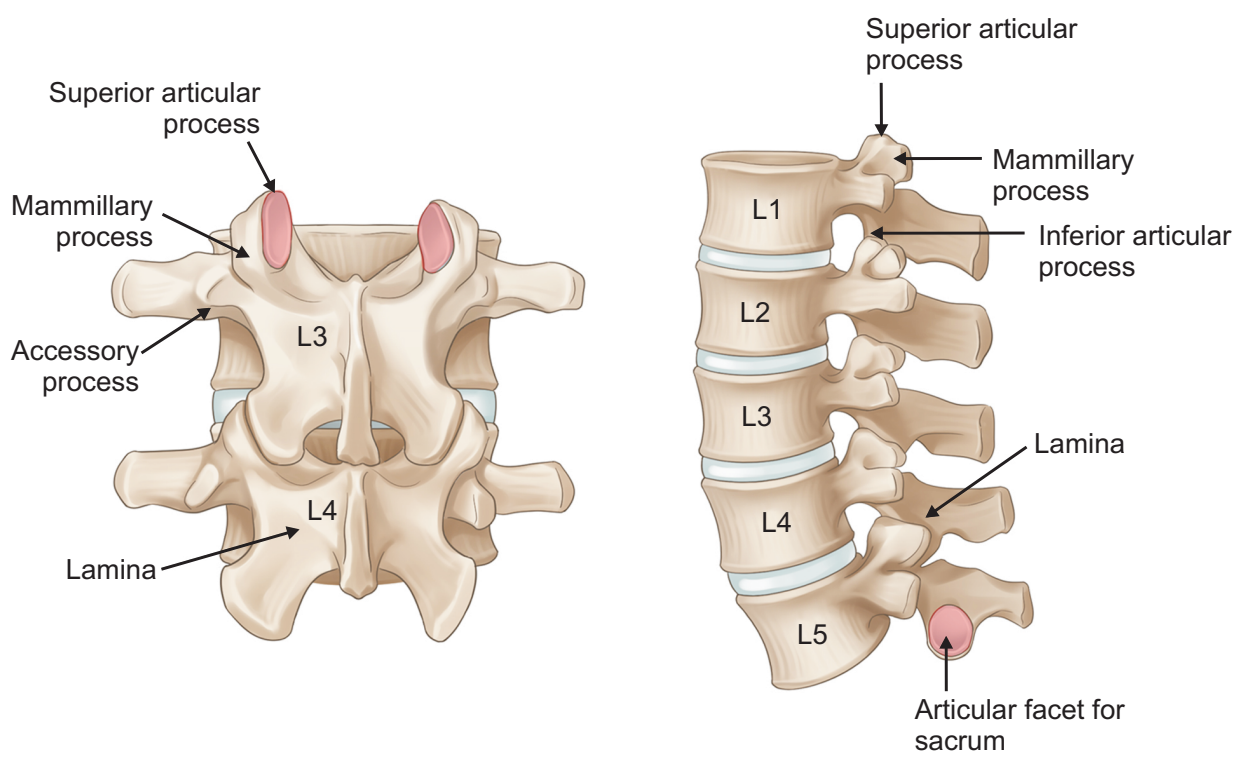

Fig. 1. Posterior and lateral views of the lumbar vertebrae and their facet joints. 
tissue pads covered by the synovial membrane, which fills the subcapsular space at the anterosuperior and posteroinferior poles of the joint. Second is fibro-adipose meniscoid covered by the synovial membrane, which projects from the joint capsule at the superior and inferior poles of the joint and enters between the articular facets. The third is connective tissue rims located along the anterior and posterior margins, which are inflections of the fibrous layer of the capsule.

Each lumbar facet joint has a distinct space capable of accommodating 1-1.5 ml of fluid [12].

\section{Innervation}

The lumbar facet joint is innervated by the medial branch from the posterior ramus of the lumbar spinal nerve. This branch also supplies the multifidus, intertransversarii mediales, interspinales, and interspinous ligament [13]. The course of the medial branch is clinically important for the successful management of LBP because this branch provides sensory innervation to the facet joint. Lau et al. [14] described the courses of the branches at each segmental level as follows (Fig. 3). (1) The medial branches from the posterior rami of L1 to L4 lumbar spinal nerves assume a constant and similar course. Each branch emerges from its intervertebral foramen and enters the posterior compartment of the back by coursing around the superior articular process below the foramen.

(2) The medial branch from the L5 posterior ramus has a dif- ferent course because the L5 posterior ramus is much longer than those of other lumbar spinal nerves. From the L5/S1 intervertebral foramen, the L5 posterior ramus runs along the groove formed between the ala of the sacrum and the superior articular process of the sacrum. Its medial branch arises and hooks medially around the caudal end of the lumbosacral facet joint [15].

Some authors have suggested that the nerve fibers from the dorsal root ganglion and paravertebral sympathetic ganglion supply the lumbar facet joint $[16,17]$, which remains unproven yet.

\section{Blood supply}

The lumbar artery arising directly from the abdominal aorta is in series with the posterior intercostal artery. Usually, there are four lumbar arteries on each side; a smaller fifth artery originates from the median sacral artery but is usually replaced by the lumbar branch of the iliolumbar artery. Each lumbar artery has a dorsal branch passing back between the adjacent transverse process of the lumbar vertebrae and a spinal branch entering the intervertebral foramen. The former supplies the lumbar facet joint as well as the adjacent muscles, fasciae, bones, red marrow, and ligaments [18].

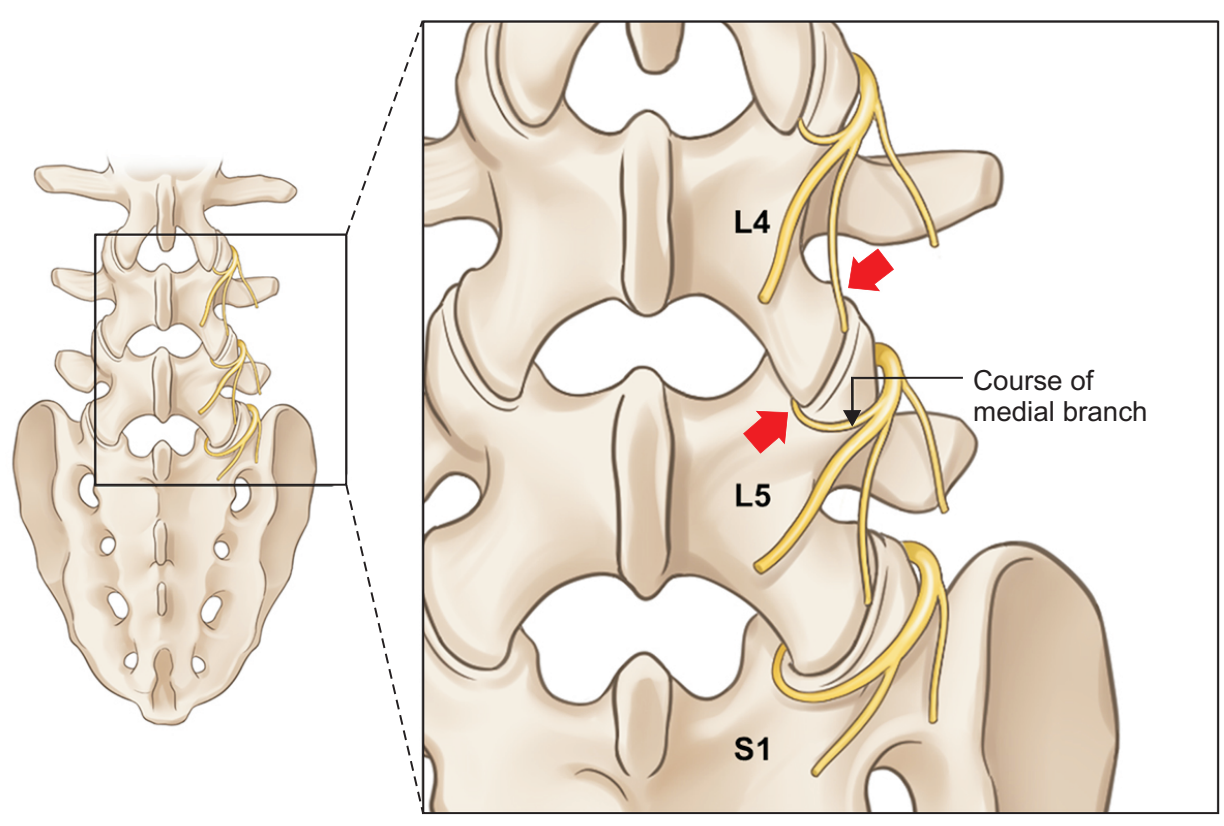

Fig. 3. The course of the medial branch of posterior ramus from the lumbar spinal nerve. Arrows indicate nerves distributing the facet joint. 


\section{PATHOPHYSIOLOGY}

The prevalence of FJP-related LBP has been extensively studied; however, its pathophysiology and diagnosis remain elusive $[19,20]$. The reported prevalence of FJP among patients with LBP varies depending on the age of the study population. It is the primary source of LBP among $15 \%$ of young adult patients and $45 \%$ of older patients $[21,22]$.

Lumbar facet joints may generate LBP and referred lower extremity pain. Stimulation of these joints, followed by saline injection, produced back pain and referred somatic pain. This provocation result is identical to the symptoms commonly seen in patients in clinical practice [23]. Previous studies regarding pain distribution showed that the pain originating from the lumbar facet joints is predominantly present in the low back, buttocks, and thighs [19,24,25]. Radiating referred pain below the knee as far as the foot has also been reported; however, typically, the pain predominantly involves the proximal parts of the lower extremities. The distance of radiation of the pain is proportional to the intensity of the pain in the back [26]. Lumbar facet joints can also be affected by segmental instability, rheumatoid arthritis, osteoarthritis, ankylosing spondylitis, and synovitis [27,28]. Injuries to the facet joints have also been reported and described in the literature as the causative origin. These include capsular avulsions or tears, subchondral fractures, intraarticular hemorrhage, and fractures of the intraarticular processes both in biomechanical and postmortem studies [15].

There are several typical pain-causing mechanisms. Within the facet joints, synovial villi may become inflamed or trapped between the articular processes related to the changes described above, resulting in pain [29]. Inflammation stimulates the nociceptive nerve endings around the facet joint by the distended capsule, which may cause LBP [30]. Additionally, compression of the nerve root emerging from the neural foramen by the expanded synovial recess may cause radiculopathy [31]. However, none of these abnormalities were observed on plain x-rays. The possibility of the meniscus or synovial entrapments causing LBP appears to be hypothetical, as it is challenging to visualize them radiologically [32,33].

In other reports, operative exposure of the facet joints revealed changes similar to those in chondromalacia of the patella $[34,35]$. Nonetheless, evidence from controlled studies has been unable to establish that FJP is due to osteoarthritis of the facet joints $[27,36]$. On plain radiographs, facet joint arthritis is commonly seen in patients with LBP, but also in asymptomatic individuals. Thus, the diagnosis of FJP cannot be established based on a radiological evaluation by either plain radiography or computerized tomography. These data also indicate that FJP is either not caused by osteoarthritis or is due to factors other than the simple radiological presence of this condition [37-39].

The postulation that facet joint arthritis is usually a secondary condition due to degenerative spinal changes, such as disc degeneration or spondylosis, may not be well-grounded, because, in at least $20 \%$ of cases, facet joint arthritis is an independent disease entity. Moreover, a correlation between discogenic pain and FJP or a combination of diseases has not yet been established [40]. Consequently, "lumbar facet joint syndrome" seems to be an unreliable clinical diagnosis [41]. Based on clinical examination alone, the specific etiology of LBP is diagnosed with certainty only in approximately $15 \%$ of patients [40]. The results of studies on FJP-related LBP suggest that the currently available tests and imaging modalities have limited or no diagnostic validity. Moreover, the history and physical examination may suggest but not confirm FJP as the source of LBP.

\section{TECHNICAL HISTORY}

Facet joints have long been recognized as a source of back pain. In 1911, Goldthwait [42] first recognized their role as a potential source of back pain. In 1933, Ghormley [43] introduced the term "facet syndrome," defining lumbosacral pain with or without sciatic pain. Later, Badgley [44] suggested that facet joints could be a primary source of pain irrespective of spinal nerve compression. They demonstrated the role of FJP in a large number of patients with LBP whose symptoms were not caused by herniated discs. The underlying physiological concept of FJP was introduced by Hirsch et al. [45] in 1963. They demonstrated that the injection of hypertonic saline into the region of the facet joints induced pain.

Concerning the fluoroscopic technique, McCall et al. [46] injected hypertonic saline into the facet joints of asymptomatic volunteers using fluoroscopy-guided technique and demonstrated the causation of back and lower extremity pain. Anatomical, technical, and diagnostic inaccuracies in 
some early reports have largely been corrected, and multiple studies have described the pattern of pain caused by facet joint stimulation $[23,46,47]$. The pain referral patterns are now widely applied in clinical practice for diagnosing FJPrelated LBP (Fig. 4). From a therapeutic point of view, Kaplan et al. [48] showed that FJP could be relieved by injecting local anesthetics into the facet joints [49].

\section{INDICATIONS}

Lumbar facet joint interventions are useful in the diagnosis and therapeutic management of chronic LBP. Controlled diagnostic facet joint blocks can be performed by injecting local anesthetics. The rationale of using facet joint blocks for diagnosis is based on the fact that lumbar facet joints are capable of causing pain, and they have a nerve supply [48,50,51]. The clinical effectiveness of diagnostic facet joint injections has been demonstrated using controlled comparative local anesthetic blocks. Based on the present comprehensive evaluation and other guidelines, lumbar facet joint injections are recommended in patients with suspected FJP [52-57]. The common indications for both diagnostic and therapeutic facet joint interventions include:

1) Average pain levels $>5$ on a scale of 0 to 10;

2) Intermittent or continuous LBP causing functional disability;

3) Somatic or non-radicular LBP and lower extremity pain lasting at least three months;
4) Failed conservative treatment, including physical therapy with exercises, chiropractic management, and pharmacologic therapy;

5) Lack of preponderance of the evidence of either discogenic or sacroiliac joint pain or evidence of radiculitis; and

6) Contraindications or inability to undergo physical therapy or inability to tolerate oral medications.

\section{TECHNIQUE}

Lumbar facet joint injections are performed by various techniques, however only the fluoroscopic-guided technique is considered reliable. It is imperative to understand the fluoroscopic anatomy. The patient is placed in the prone position on the procedure table with the fluoroscope centered over the target level. A pillow can be placed under the abdomen to facilitate easier entry into the joint, reducing lumbar curvature. For more comfortable breathing and speaking during the procedure, the patient's head and face should be supported comfortably.

As with any lumbar intervention, a baseline anteroposterior (AP) fluoroscopic view of the lumbar spine should be obtained, and the fluoroscope is oriented. Facet joints may or may not be visible on AP fluoroscopy depending on the patient's anatomic characteristics. To obtain a true AP view of the target segment, the superior vertebral endplate of the lower of the two vertebrae is "squared off." This way, the $\mathrm{X}$ -

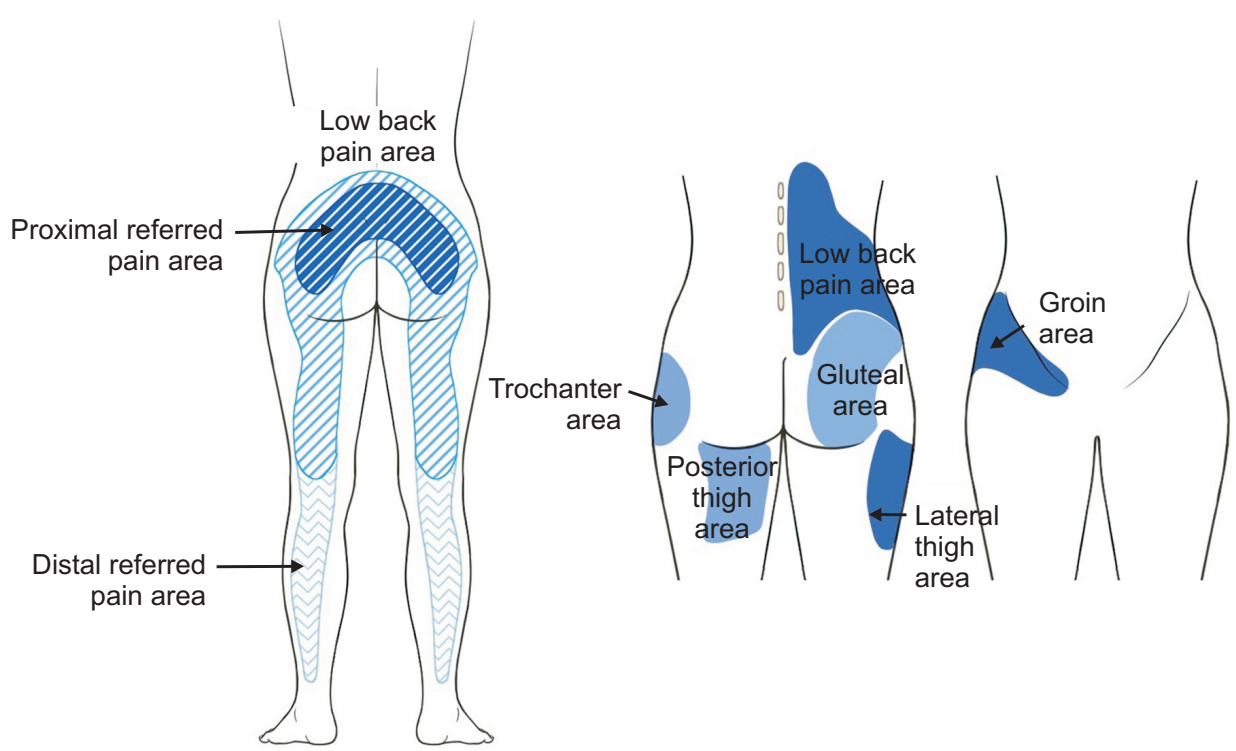

Fig. 4. Illustration of distribution pattern related to facet joint pain. 
ray beam passes parallel to the endplate and appears as a dense transverse line (Fig. 5). Once the fluoroscopic view of

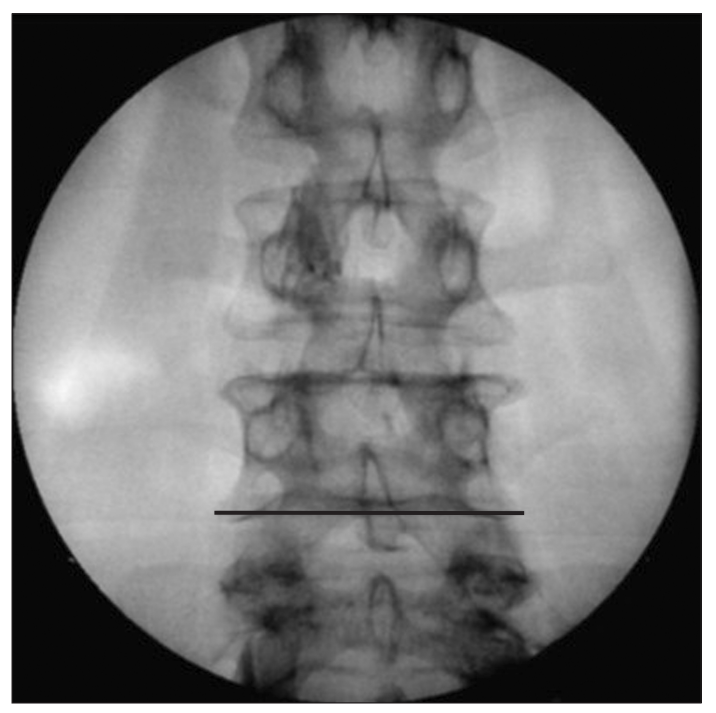

Fig. 5. A true anteroposterior view of the target segment. the target joint is obtained, the fluoroscopy beam is rotated from the AP view toward the oblique view until the target facet joint is well visualized, denoted by the presence of the "Scottie dog" sign (Fig. 6). The upper lumbar facet joints are typically aligned toward the sagittal plane and may be visible on AP imaging, whereas the lower joints are typically oriented toward the coronal plane and can be identified on oblique imaging. Then the target joint is visualized under fluoroscopic guidance, and the skin may be marked.

A 22-25 gauge 31/2-inch spinal needle is inserted through the anesthetized area. The gauge used is a matter of physician experience, preference, and skill. However, fine needles tend to deflect off course during their passage through the back muscles. The needle is directed downward and obliquely (from lateral to medial) toward the targeted joint under fluoroscopic guidance. The target point is the medial edge of the superior articular process, opposite the center of the joint cavity. The lateral edge of the inferior articular process can
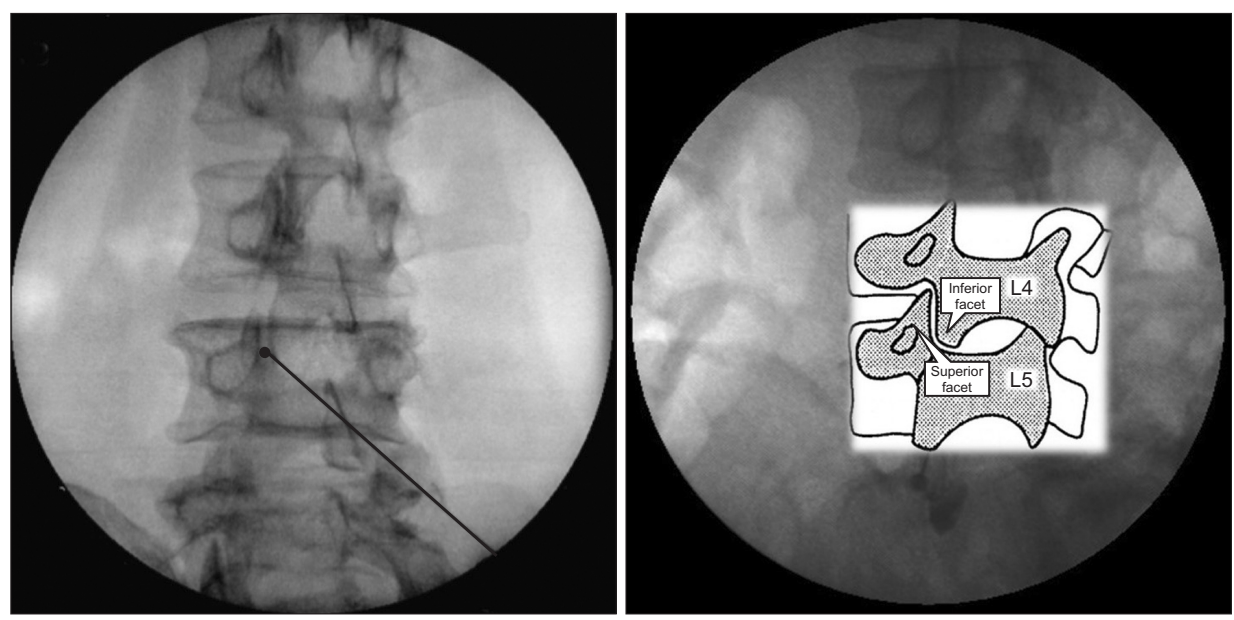

Fig. 6. Oblique view of the target segment and "Scotty dog".
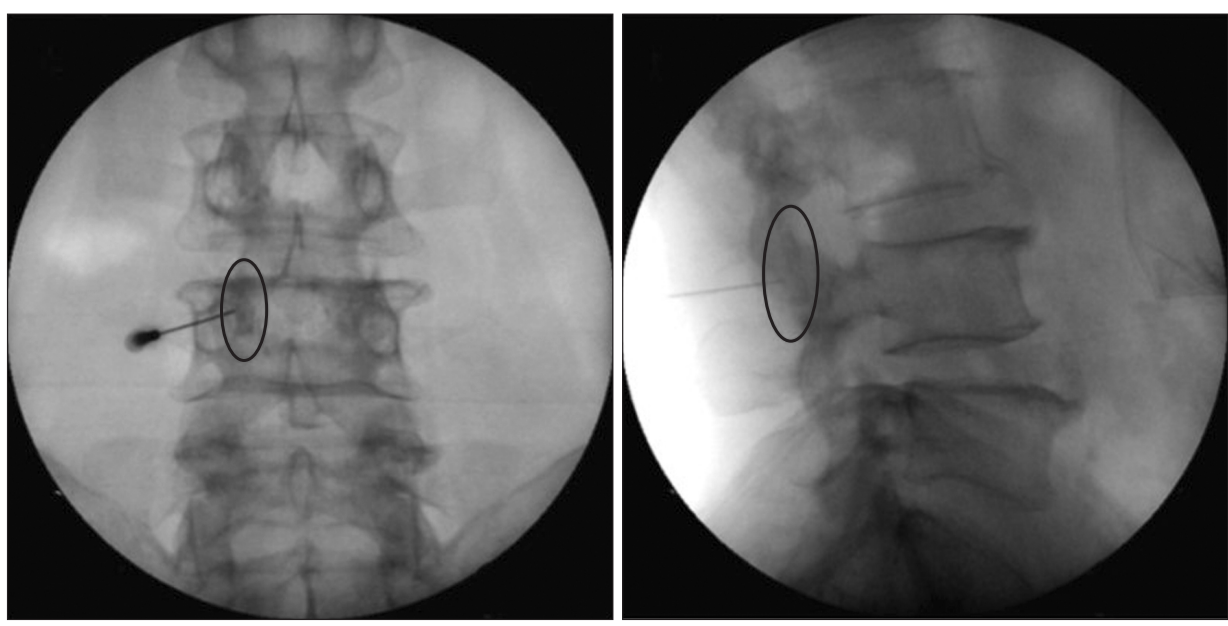

Fig. 7. Anteroposterior and lateral view of the facet joint injection. 
serve just as well, but the superior articular process is slightly larger and somewhat more readily recognized (Fig. 1). After contact is made with the inferior or superior articular processes, the needle is slightly withdrawn and redirected to enter the superior or inferior capsular recesses above or below the joint. Needle advancement is stopped when the needle is felt to penetrate the target facet joint to prevent any potential damage to the articular cartilage (Fig. 7). The physician may even feel a loss of resistance as the needle passes through the joint capsule. However, entry is sometimes not readily achieved due to structural changes. In such cases, despite the tip of the needle appearing to lie over the joint cavity, the needle keeps encountering resistance, as if it is still lying on the bone. If there is difficulty in obtaining capsular penetration, one may try to access the articular recesses by redirecting the needle just off the margins of the inferior articular process (Fig. 8). Some joints with severe arthritic changes may have lost their cartilage and are so severely narrowed that needle entrance may be impossible. Once the position of the needle is considered appropriate, $0.2-0.5 \mathrm{ml}$ of contrast medium is injected into the joint to confirm the joint capsule, and an arthrographic image (arthrogram) is obtained [53]. The contrast medium outlines the joint cavity in the form of a linear streak between the articular surfaces, with small blobs in either or both of the superior and inferior subcapsular pockets. During contrast injection, the outline of the oval-shaped joint capsule should be visualized with a lack of vascular uptake and/ or intramuscular spread (Fig. 9). After intraarticular needle tip placement has been confirmed, an anesthetic agent alone is injected into the joint for a diagnostic block or in combination with a steroid for a therapeutic block.

\section{COMPLICATIONS AND CLINICAL PEARLS}

Complications from facet joint injections in the lumbar spine are exceedingly rare [58], and mostly related to the needle placement and the administration of various drugs. In a large study that evaluated over 43,000 facet joint injections, intravascular penetration and local hematoma were observed only in $4 \%$ and $1.2 \%$ of cases, respectively. At the same time, the incidence of profuse bleeding, soreness, nerve root irritation, and other effects, such as vasovagal reactions, was $1 \%$ [59]. The most common problems included local swelling, pain at the site of needle insertion, and LBP, and known to be short-lived and self-limited.

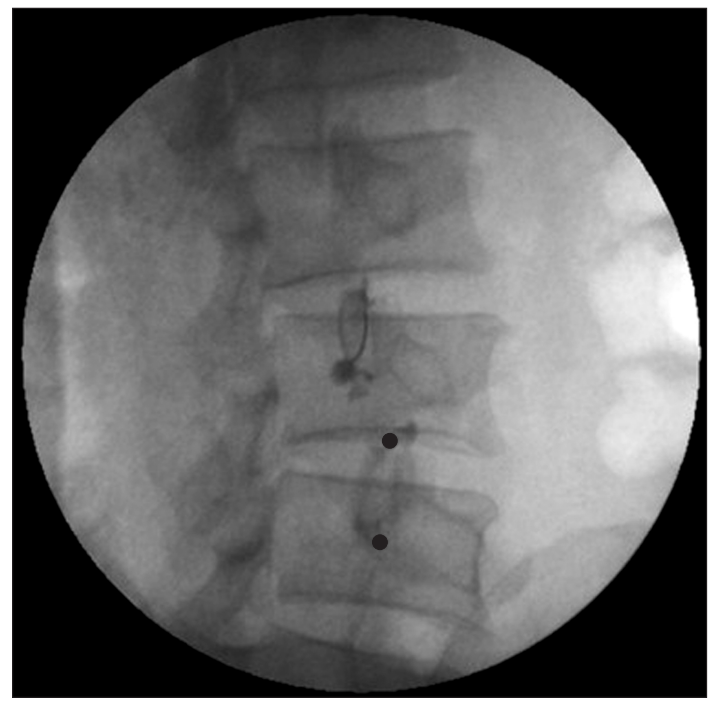

Fig. 8. Needle position and facet joint. Superior or inferior articular processes could be targeted.
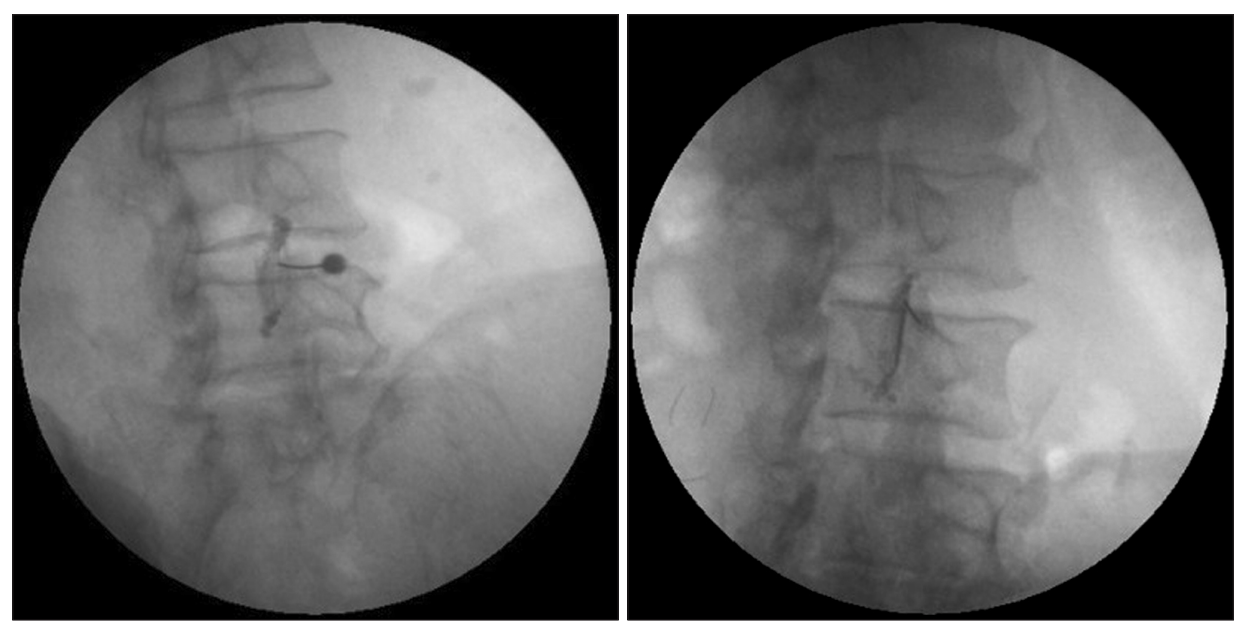

Fig. 9. Facet joint after contrast injection. Oval shaped or linear streak capsules are shown. 


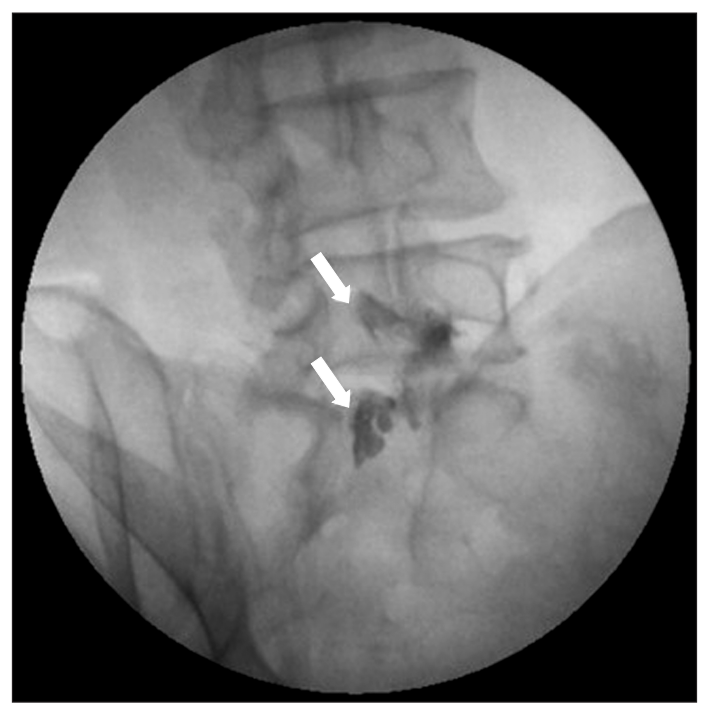

Fig. 10. Aberrant contrast leakage into the epidural space during facet joint injection.

Occasionally, aberrant patterns of contrast flow may be encountered. In addition to intravascular penetration, epidural leakage is frequently observed during facet joint injections (Fig. 10). In recent reports, the epidural leakage was considered the result of the rupture of the facet joint capsule [60-62]. In such cases, an alternative approach with epidural injection may be considered. Furthermore, this calls for the attention of pain physicians due to the possibility of developing motor weakness after facet joint injection or epidural injection.

\section{CLINICAL EVIDENCE}

Regarding clinical evidence of the therapeutic efficacy of facet joint injections, two randomized trials stand out. The first was a high quality, randomized, double-blind, placebo or active-control trial by Carette et al. [63] in which the results were negative. The other was a moderate-quality study by Fuchs et al. [64] in which a weakly positive or undetermined effect was found for a high number of injections. Among the nonrandomized studies, six provided clinical evidence. Five of these studies reported positive results after facet joint injections [65-68], whereas one study reported a negative result [69]. Based on the above, the clinical evidence for the efficacy of facet joint injections is considered limited [70].

Another randomized, controlled clinical trial evaluated the effectiveness of lumbar facet joint injections [71]. A total of 229 participants were enrolled to receive facet injections with bupivacaine and steroid, medial branch blocks, or saline. The results of this study showed that facet joint injections had little long-term therapeutic utility, but had a prognostic value compared to control injections before radiofrequency ablation. Thus, this study's results emphasized the diagnostic value of facet joint injections.

Concerning the approach technique, there has been increasing interest in the use of ultrasound (US) to guide needle placement for facet joint injection. Compared with the fluoroscopic-guided technique, the distinct advantages of US guidance include real-time visualization of the needle, target structure, injectate, and the surrounding tissue. A study by Galiano et al. reported the feasibility of US-guided facet joint injections in cadavers [72]. In this study, the US was considered superior to computed tomographic-guided lumbar facet joint injection; however, the study included a small sample size of 40 patients, and lower success rates were obtained in obese patients. Hence, no recommendations can currently be given regarding the superiority of the US over fluoroscopy [73].

\section{CONCLUSIONS}

FJP is not diagnosed by demographic features, pain characteristics, physical findings, electrodiagnostic studies, or radiological evaluation as other types of LBP. Diagnostic blocks using comparative local anesthetic blocks or placebo injections are the only reliable diagnostic measures according to the current literature. Their validity, specificity, and sensitivity are considered reliable in the diagnosis of FJP. Facet joint-related anatomical, clinical, and technical knowledge is essential for successful pain management. Pain physicians should embrace all aspects of FJP management, from diagnosis to interventional management.

\section{CONFLICTS OF INTEREST}

No potential conflict of interest relevant to this article was reported.

\section{ORCID}

Hyung-Sun Won, https://orcid.org/0000-0001-6084-6698

Miyoung Yang, https://orcid.org/0000-0002-4748-6007 


\section{REFERENCES}

1. Manchikanti L, Pampati V, Hirsch JA. Utilization of interventional techniques in managing chronic pain in medicare population from 2000 to 2014: an analysis of patterns of utilization. Pain Physician 2016; 19: E531-46.

2. Boswell MV, Shah RV, Everett CR, Sehgal N, McKenzie Brown $\mathrm{AM}$, Abdi S, et al. Interventional techniques in the management of chronic spinal pain: evidence-based practice guidelines. Pain Physician 2005; 8: 1-47.

3. Boswell MV, Trescot AM, Datta S, Schultz DM, Hansen HC, Abdi $\mathrm{S}$, et al. Interventional techniques: evidence-based practice guidelines in the management of chronic spinal pain. Pain Physician 2007; 10: 7-111.

4. Manchikanti L. Medicare in interventional pain management: a critical analysis. Pain Physician 2006; 9: 171-97.

5. Manchikanti L. The growth of interventional pain management in the new millennium: a critical analysis of utilization in the medicare population. Pain Physician 2004; 7: 465-82.

6. Manchikanti L, Singh V, Pampati V, Damron KS, Barnhill RC, Beyer $\mathrm{C}$, et al. Evaluation of the relative contributions of various structures in chronic low back pain. Pain Physician 2001; 4: 30816.

7. Schwarzer AC, Wang SC, Bogduk N, McNaught PJ, Laurent R. Prevalence and clinical features of lumbar zygapophysial joint pain: a study in an Australian population with chronic low back pain. Ann Rheum Dis 1995; 54: 100-6.

8. Woodburne RT, Burkel WE. Essentials of human anatomy. 9th ed. Oxford, Oxford University Press. 1994, 347 p.

9. Soames RW. Skeletal system. In: Gray's Anatomy. 38th ed. Edited by Gray H, Williams PL, Bannister LH: New York, Churchill Livingstone. 1995, pp 425-736.

10. Rosse C, Gaddum-Rosse P, Hollinshead WH. Hollinshead's textbook of anatomy. 5th ed. Philadelphia, Lippincott-Raven. 1997, pp 126-7.

11. Engel R, Bogduk N. The menisci of the lumbar zygapophysial joints. J Anat 1982; 135: 795-809.

12. Glover JR. Arthrography of the joints of the lumbar vertebral arches. Orthop Clin North Am 1977; 8: 37-42.

13. Bogduk N. The innervation of the lumbar spine. Spine (Phila Pa 1976) 1983; 8: 286-93.

14. Lau P, Mercer S, Govind J, Bogduk N. The surgical anatomy of lumbar medial branch neurotomy (facet denervation). Pain Med 2004; 5: 289-98.

15. Cohen SP, Raja SN. Pathogenesis, diagnosis, and treatment of lumbar zygapophysial (facet) joint pain. Anesthesiology 2007; 106: 591-614.
16. Pedersen HE, Blunck CF, Gardner E. The anatomy of lumbosacral posterior rami and meningeal branches of spinal nerve (sinu-vertebral nerves); with an experimental study of their functions. J Bone Joint Surg Am 1956; 38-A: 377-91.

17. Suseki K, Takahashi Y, Takahashi K, Chiba T, Tanaka K, Morinaga $\mathrm{T}$, et al. Innervation of the lumbar facet joints. Origins and functions. Spine (Phila Pa 1976) 1997; 22: 477-85.

18. Gabella G. Cardiovascular system. In: Gray's Anatomy. 38th ed. Edited by Gray H, Williams PL, Bannister LH: New York, Churchill Livingstone. 1995, 1558 p.

19. Boswell MV, Singh V, Staats PS, Hirsch JA. Accuracy of precision diagnostic blocks in the diagnosis of chronic spinal pain of facet or zygapophysial joint origin. Pain Physician 2003; 6: 449-56.

20. Cavanaugh JM, Lu Y, Chen C, Kallakuri S. Pain generation in lumbar and cervical facet joints. J Bone Joint Surg Am 2006; 88 Suppl 2: 63-7.

21. Manchikanti L, Pampati V, Fellows B, Bakhit CE. Prevalence of lumbar facet joint pain in chronic low back pain. Pain Physician 1999; 2: 59-64.

22. Saravanakumar K, Harvey A. Lumbar zygapophyseal (facet) joint pain. Rev Pain 2008; 2: 8-13.

23. Marks R. Distribution of pain provoked from lumbar facet joints and related structures during diagnostic spinal infiltration. Pain 1989; 39: 37-40.

24. Windsor RE, King FJ, Roman SJ, Tata NS, Cone-Sullivan LA, Thampi S, et al. Electrical stimulation induced lumbar medial branch referral patterns. Pain Physician 2002; 5: 347-53.

25. Sehgal N, Dunbar EE, Shah RV, Colson J. Systematic review of diagnostic utility of facet (zygapophysial) joint injections in chronic spinal pain: an update. Pain Physician 2007; 10: 213-28.

26. Mooney V, Robertson J. The facet syndrome. Clin Orthop Relat Res 1976; (115): 149-56

27. Borenstein D. Does osteoarthritis of the lumbar spine cause chronic low back pain? Curr Pain Headache Rep 2004; 8: 512-7.

28. Igarashi A, Kikuchi S, Konno S, Olmarker K. Inflammatory cytokines released from the facet joint tissue in degenerative lumbar spinal disorders. Spine (Phila Pa 1976) 2004; 29: 2091-5.

29. Hadley LA. Anatomico-roentgenographic studies of the posterior spinal articulations. Am J Roentgenol Radium Ther Nucl Med 1961; 86: 270-6.

30. Dory MA. Arthrography of the lumbar facet joints. Radiology 1981; 140: 23-7.

31. Maldague B, Mathurin P, Malghem J. Facet joint arthrography in lumbar spondylolysis. Radiology 1981; 140: 29-36.

32. Twomey LT. A rationale for the treatment of back pain and joint pain by manual therapy. Phys Ther 1992; 72: 885-92.

33. Lippitt AB. The facet joint and its role in spine pain. Manage- 
ment with facet joint injections. Spine (Phila Pa 1976) 1984; 9: 746-50.

34. Cavanaugh JM, Ozaktay AC, Yamashita HT, King AI. Lumbar facet pain: biomechanics, neuroanatomy and neurophysiology. J Biomech 1996; 29: 1117-29.

35. Grönblad M, Korkala O, Konttinen YT, Nederström A, Hukkanen M, Tolvanen E, et al. Silver impregnation and immunohistochemical study of nerves in lumbar facet joint plical tissue. Spine (Phila Pa 1976) 1991; 16: 34-8.

36. Kang YM, Choi WS, Pickar JG. Electrophysiologic evidence for an intersegmental reflex pathway between lumbar paraspinal tissues. Spine (Phila Pa 1976) 2002; 27: E56-63.

37. Schwarzer AC, Wang SC, O’Driscoll D, Harrington T, Bogduk $\mathrm{N}$, Laurent R. The ability of computed tomography to identify a painful zygapophysial joint in patients with chronic low back pain. Spine (Phila Pa 1976) 1995; 20: 907-12.

38. Magora A, Bigos SJ, Stolov WC, Tomsli MA, Magora F, Vatine JJ. The significance of medical imaging findings in low back pain. Pain Clinic 1994; 7: 99-105.

39. Weishaupt D, Zanetti M, Hodler J, Boos N. MR imaging of the lumbar spine: prevalence of intervertebral disk extrusion and sequestration, nerve root compression, end plate abnormalities, and osteoarthritis of the facet joints in asymptomatic volunteers. Radiology 1998; 209: 661-6.

40. Manchikanti L, Boswell MV, Singh V, Pampati V, Damron KS, Beyer CD. Prevalence of facet joint pain in chronic spinal pain of cervical, thoracic, and lumbar regions. BMC Musculoskelet Disord 2004; 5: 15.

41. Jackson RP. The facet syndrome. Myth or reality? Clin Orthop Relat Res 1992; (279): 110-21.

42. Goldthwait JE. The lumbo-sacral articulation. An explanation of many cases of "Lumbago," "Sciatica" and Paraplegia. Boston Med Surg J 1911; 164: 365-72.

43. Ghormley RK. Low back pain. With special reference to the articular facets, with presentation of an operative procedure. JAMA 1933; 101: 1773-7.

44. Badgley CE. The articular facets in relation to low-back pain and sciatic radiation. J Bone Joint Surg 1941; 23: 481-96.

45. Hirsch C, Ingelmark BE, Miller M. The anatomical basis for low back pain. Studies on the presence of sensory nerve endings in ligamentous, capsular and intervertebral disc structures in the human lumbar spine. Acta Orthop Scand 1963; 33: 1-17.

46. McCall IW, Park WM, O'Brien JP. Induced pain referral from posterior lumbar elements in normal subjects. Spine (Phila Pa 1976) 1979; 4: 441-6.

47. Fukui S, Ohseto K, Shiotani M, Ohno K, Karasawa H, Naganuma Y. Distribution of referred pain from the lumbar zygapophyseal joints and dorsal rami. Clin J Pain 1997; 13: 303-7.

48. Kaplan M, Dreyfuss P, Halbrook B, Bogduk N. The ability of lumbar medial branch blocks to anesthetize the zygapophysial joint. A physiologic challenge. Spine (Phila Pa 1976) 1998; 23: 1847-52.

49. Dreyfuss P, Schwarzer AC, Lau P, Bogduk N. Specificity of lumbar medial branch and L5 dorsal ramus blocks. A computed tomography study. Spine (Phila Pa 1976) 1997; 22: 895-902.

50. Barnsley L, Lord S, Bogduk N. Comparative local anaesthetic blocks in the diagnosis of cervical zygapophysial joint pain. Pain 1993; 55: 99-106.

51. Lord SM, Barnsley L, Bogduk N. The utility of comparative local anesthetic blocks versus placebo-controlled blocks for the diagnosis of cervical zygapophysial joint pain. Clin J Pain 1995; 11: 208-13.

52. Datta S, Lee M, Falco FJ, Bryce DA, Hayek SM. Systematic assessment of diagnostic accuracy and therapeutic utility of lumbar facet joint interventions. Pain Physician 2009; 12: 437-60.

53. Bogduk N. International Spinal Injection Society guidelines for the performance of spinal injection procedures. Part 1: zygapophysial joint blocks. Clin J Pain 1997; 13: 285-302.

54. Manchikanti L, Boswell MV, Singh V, Benyamin RM, Fellows $\mathrm{B}$, Abdi S, et al. Comprehensive evidence-based guidelines for interventional techniques in the management of chronic spinal pain. Pain Physician 2009; 12: 699-802.

55. Manchikanti L, Datta S, Derby R, Wolfer LR, Benyamin RM, Hirsch JA. A critical review of the American Pain Society clinical practice guidelines for interventional techniques: part 1. diagnostic interventions. Pain Physician 2010; 13: E141-74.

56. Manchikanti L, Datta S, Gupta S, Munglani R, Bryce DA, Ward SP, et al. A critical review of the American Pain Society clinical practice guidelines for interventional techniques: part 2. Therapeutic interventions. Pain Physician 2010; 13: E215-64.

57. Chou R, Atlas SJ, Stanos SP, Rosenquist RW. Nonsurgical interventional therapies for low back pain: a review of the evidence for an American Pain Society clinical practice guideline. Spine (Phila Pa 1976) 2009; 34: 1078-93.

58. Manchikanti L, Kaye AD, Boswell MV, Bakshi S, Gharibo CG, Grami V, et al. A systematic review and best evidence synthesis of the effectiveness of therapeutic facet joint interventions in managing chronic spinal pain. Pain Physician 2015; 18: E535-82.

59. Manchikanti L, Malla Y, Wargo BW, Cash KA, Pampati V, Fellows B. Complications of fluoroscopically directed facet joint nerve blocks: a prospective evaluation of 7,500 episodes with 43,000 nerve blocks. Pain Physician 2012; 15: E143-50.

60. Schulte TL, Pietilä TA, Heidenreich J, Brock M, Stendel R. Injection therapy of lumbar facet syndrome: a prospective study. Acta Neurochir (Wien) 2006; 148: 1165-72. 
61. Shih C, Lin GY, Yueh KC, Lin JJ. Lumbar zygapophyseal joint injections in patients with chronic lower back pain. J Chin Med Assoc 2005; 68: 59-64.

62. Kim S, Lee JW, Chai JW, Lee GY, You JY, Kang HS, et al. Fluoroscopy-guided intra-articular facet joint steroid injection for the management of low back pain: therapeutic effectiveness and arthrographic pattern. J Korean Soc Radiol 2015; 73: 172-80.

63. Carette S, Marcoux S, Truchon R, Grondin C, Gagnon J, Allard $\mathrm{Y}$, et al. A controlled trial of corticosteroid injections into facet joints for chronic low back pain. N Engl J Med 1991; 325: 1002-7.

64. Fuchs S, Erbe T, Fischer HL, Tibesku CO. Intraarticular hyaluronic acid versus glucocorticoid injections for nonradicular pain in the lumbar spine. J Vasc Interv Radiol 2005; 16: 1493-8.

65. Murtagh FR. Computed tomography and fluoroscopy guided anesthesia and steroid injection in facet syndrome. Spine (Phila Pa 1976) 1988; 13: 686-9.

66. Destouet JM, Gilula LA, Murphy WA, Monsees B. Lumbar facet joint injection: indication, technique, clinical correlation, and preliminary results. Radiology 1982; 145: 321-5.

67. Celik B, Er U, Simsek S, Altug T, Bavbek M. Effectiveness of lumbar zygapophysial joint blockage for low back pain. Turk Neuro- surg 2011; 21: 467-70.

68. Anand S, Butt MS. Patients' response to facet joint injection. Acta Orthop Belg 2007; 73: 230-3.

69. Bani A, Spetzger U, Gilsbach JM. Indications for and benefits of lumbar facet joint block: analysis of 230 consecutive patients. Neurosurg Focus 2002; 13: E11.

70. Falco FJ, Manchikanti L, Datta S, Sehgal N, Geffert S, Onyewu O, et al. An update of the effectiveness of therapeutic lumbar facet joint interventions. Pain Physician 2012; 15: E909-53.

71. Cohen SP, Doshi TL, Constantinescu OC, Zhao Z, Kurihara C, Larkin TM, et al. Effectiveness of lumbar facet joint blocks and predictive value before radiofrequency denervation: the facet treatment study (FACTS), a randomized, controlled clinical trial. Anesthesiology 2018; 129: 517-35.

72. Galiano K, Obwegeser AA, Bodner G, Freund M, Maurer H, Kamelger FS, et al. Ultrasound guidance for facet joint injections in the lumbar spine: a computed tomography-controlled feasibility study. Anesth Analg 2005; 101: 579-83.

73. Narouze SN. Ultrasound-guided interventional procedures in pain management: evidence-based medicine. Reg Anesth Pain Med 2010; 35(2 Suppl): S55-8. 